\title{
Integration between Green Quality Function Deployment, Modularity Concept and Life Cycle Assessment Toward Sustainable Product Design
}

\author{
Heru Prastawa, Sri Hartini, Mohamat Anshori, Siechara Hans, Christoper Wimba \\ Industrial Engineering Program, Diponegoro University, Prof. H. Soedarto, SH. Semarang, \\ Indonesia
}

\begin{abstract}
The design phase is recognized as a key phase in the application of sustainable manufacturing concepts. Green Quality Function Deployment (GQFD) and modularity play an important role in product design. Green Quality Function Deployment produces technical parameters that represent the needs of consumers while taking into account environmental aspects. Modularity benefits manufacturing and flexibility in facing adjustments and changes. Integration of GQFD and modularity is expected to generate synergistic gains from both. The results are measured by life cycle assessment (LCA) to determine the impact of the product on the environment. This study shows that GQFD, modularity and LCA integration in realizing sustainable product design is worthy of consideration. The case study was conducted with the fan because the product is very needed in the tropics, such as Indonesia.
\end{abstract}

\section{Introduction}

Increased public awareness and government regulation on environmental protection challenge product designers to consider environmental aspects of product design goals [1]. The design phase has been widely recognized as a key phase in the product life cycle in the application of sustainable manufacturing [2]. The design of a product will affect the next stage, such as material requirements, manufacturing process, energy consumption, and activity at the product disposal stage [1]. $80 \%$ of the cost of development, production, and use of the product is determined by the initial design stage [3]. The earlier the design team considers the environmental factors in the product life cycle, the greater its potential for environmental benefit and cost reduction.

Quality Function Deployment (QFD) is a method that transforms consumer needs into engineering parameters in design and production. From 1993 to 2009, there were 17 ecodesign methods developed based on QFD [4]). The first method was developed to improve the quality and cost of eco-design with integrating environmental aspects into the product specification matrix [5]. Then QFD integrated with other methods, such as 3D-QFDE, QFDE/LCA, QFDE/LCA/TRIZ [6-7] and adding environmental criteria as consumer needs [8]. But this integration has not involved the concept of modularity. Modular design can 
increase the flexibility and availability of adjustments and changes [9], reducing the number of components [10]), reducing cost and development time [11-12], reducing environmental impact $[7,12]$.

This research intends to develop the design concept by integrating Green QFD and modularity design. The results of the integration will be compared using the LCA method. The LCA has the ability to discover important environmental issues [14-15] and is a highly representative tool for analyzing and quantifying resource consumption and environmental impacts on throughout the product life cycle [1]. LCA is often used to compare related product alternatives based on environmental impacts making it easier to know which alternatives are the most environmentally friendly [14]. Case studies were conducted on a fan, electronic products among the lower and middle class in hot climates. Electronic products produce many the environment impact [16]. About 50 million tons of electronic waste is produced annually and less than $10 \%$ are recycled [17]. If this is allowed to happen without a precautionary measure, electronic waste can be a threat to the preservation of the earth's environment

\section{Research Method}

The purpose of product design development by integrating Green QFD, modularity and LCA is to gain synergistic advantages from the three methods. The product design that meets the needs of the consumers is profitable for the manufacturer and also environmentally friendly. Fig 1 is a framework of development model to achieve goals.

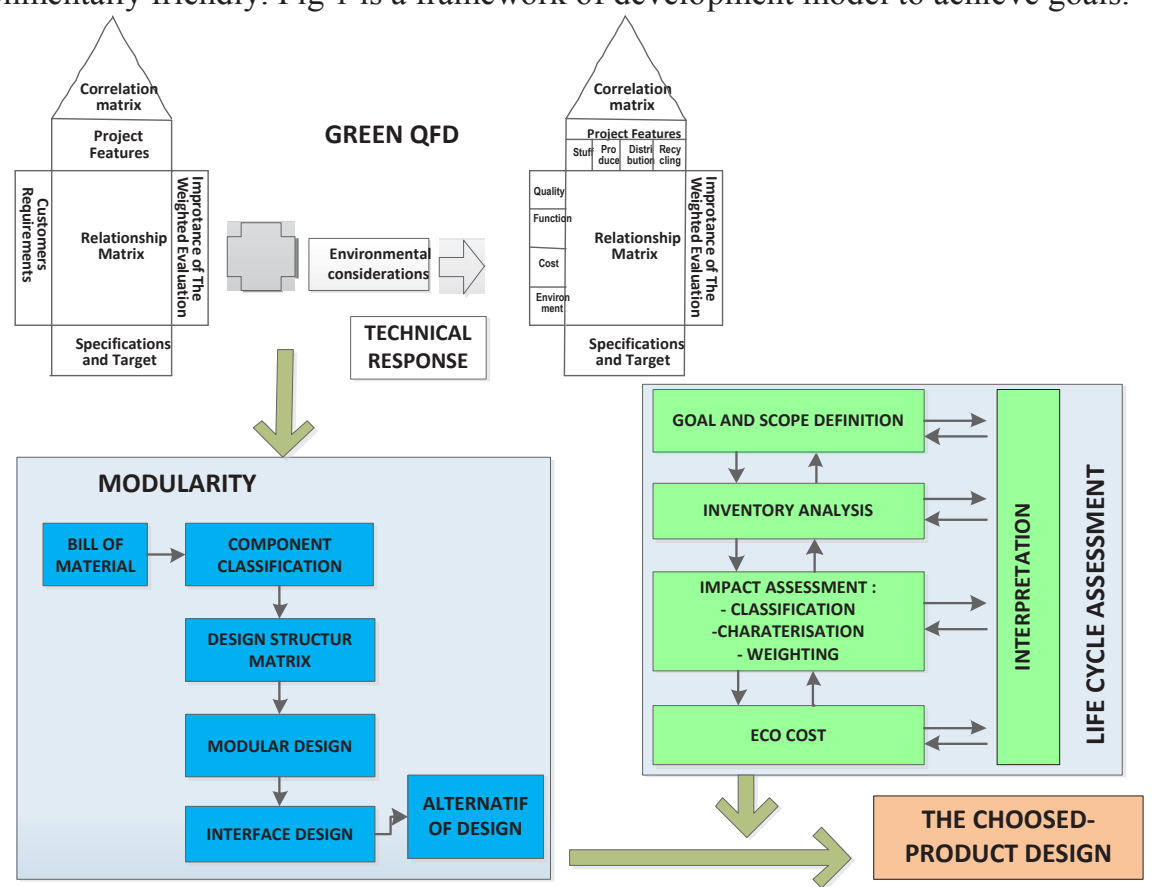

Fig 1. Framework integration GQFD-modularity-LCA

The Green QFD consists of voices of customers matrix, engineering matrix, the house of quality, benchmark, and roof. Voice of customers contains the questionnaire data. The engineering matrix contains technical response factors. The quality hypothesis is a matrix that shows the relationship each indicator of the voice of customers and each factor of the technical responses. Benchmark shows the comparative data of respondents' assessment of 
the products on the market. The Roof is a matrix that shows the influence of a factor in engineering matrix on other factors. Green QFD was developed by adding environmental criteria in exploring consumer desires. Table 1 presents the dimensions and variables used. This data will then become the voice of customers. Questionnaire method is done to the consumer to know the needs of the consumer. Consumers are selected randomly in the city of Semarang and surrounding areas. Respondents are confirmed as users of fans who have experienced damage. The Proposed design is made to develop products based on the most important criteria according to consumers. House of quality would be developed based on the results of this questionnaire. Benchmark did on stand fan as the best-selling fan of three companies with demand greatest. Consumers are required to provide an assessment of the 3 products based on the assessment variable. The weight calculation for each model is taken based on the most choice of respondents. This weight is then multiplied by the weighted value of the relationship between the voices of customers with technical responses (weight of the house of quality).

Modular design concept can simplify the change of product design as a whole. As an independent module, in case of design change, it is not necessary to change the design core in each module. There are three main features of the module, namely: separable, isolable and re-combinable [18].

The LCA method calculation is performed using SimaPro v 7.1.8 software for evaluating the environmental impact value of the fan product. The LCA has 4 stages, the goal and scope definition, inventory analysis, impact assessment and calculate eco-cost. Eco-Cost is a cost that must be spent to reduce environmental pollution according to the ability of the earth. The Eco-Cost calculation uses 2012 eco-cost method using Eco-Invent V3 2014.

Table 1. Dimensions and Variables used in Green QFD

\begin{tabular}{|c|l|l|}
\hline No & Dimensions & \multicolumn{1}{c|}{ Variable } \\
\hline 1 & Appearance & Size [19];[20], Color [20] \\
\hline 2 & Service & Price [19];[21], Easy to assemble/disassemble [20] \\
\hline 3 & Functionality & Multifunction [22], Features replacement speed of rotation [20] \\
\hline 4 & Responsiveness & Weight [23], Ergonomic [23] \\
\hline 5 & Reliability & $\begin{array}{l}\text { Not noisy [23], Stable Usage [23], Easy to clean [8], Easy to maintain } \\
{[20]}\end{array}$ \\
\hline 6 & Environmental & $\begin{array}{l}\text { Recyclable [20], Save energy [19], Not using harmful materials (toxic) } \\
\text { [20], The life of the material [23], Easy to reuse [23], Number of } \\
\text { components (less material use) [23] }\end{array}$ \\
\hline
\end{tabular}

\section{Result and Discussion}

Based on the questionnaire, the top five criteria are durable, energy efficient, not noisy, easy to repair, and do not use hazardous materials. The life time of the fan does not match the expectations of consumers during this. Besides, to repair a broken fan is not an easy thing. $63 \%$ of respondents state that it is difficult to replace the broken component of the fan. This condition triggers behavior for buying a new fan (24\%). Oftenly, the damage of one vital component causes the fan becomes disturbed for example motor. If the motor is damaged, although the other components are still good condition, the fan can't use. The life time of the fan becomes more shorter than standard. Furthermore, the increase in the volume of waste will also cause economic loss and a negative effect on the environment [24].

The factor of engineering matrix that needs to be considered is using the non-permanent connection. This factor makes the fan easy to be disassembled and re-installed. It certainly 
facilitate the user in performing maintenance or minor repairs. This design also has a positive impact on the environment. The use of screws and bolts can reduce chemicals in the connection technique and more easily dismantled without damaging the connection.

The next important factor is the selection of materials. The correspondent wants a fan that is free from hazardous materials. Some ingredients that are proven toxic and should not be used are listed in the Restriction of Hazardous Substances directive. Aluminum may be considered as having high recyclability, low cost, light weight, corrosion resistance, and are not harmful to humans and the environment. Polypropylene is a mild and sufficient plastic strong; not dangerous, easy to recycle, and not easy to absorb dirt so easy to clean. It is in accordance with the wishes of the consumer, which is easy to clean.

Table 2. The comparison between the current fan with the proposed.

\begin{tabular}{|c|c|c|c|c|}
\hline & $\begin{array}{l}\text { Existing: fixed and } \\
\text { single function }\end{array}$ & $\begin{array}{c}\text { Modular, single } \\
\text { function }\end{array}$ & $\begin{array}{c}\text { Fixed, } \\
\text { multifunction }\end{array}$ & $\begin{array}{c}\text { Modular } \\
\text { Multifunction* }\end{array}$ \\
\hline 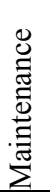 & $\begin{array}{l}\text { Difficult, especially the } \\
\text { dynamo as a framework } \\
\text { that integrates with the } \\
\text { main electrical } \\
\text { installation }\end{array}$ & $\begin{array}{l}\text { Easier, because the } \\
\text { modular system } \\
\text { makes it easy to } \\
\text { uninstall. }\end{array}$ & $\begin{array}{l}\text { Difficult, the dynamo } \\
\text { system is still the } \\
\text { same as the current } \\
\text { fan. }\end{array}$ & $\begin{array}{l}\text { Easy, because } \\
\text { of the modular } \\
\text { concept and } \\
\text { system } \\
\text { connector }\end{array}$ \\
\hline 焉 & $\begin{array}{l}\text { All products have the } \\
\text { potential to become } \\
\text { waste, even if only the } \\
\text { damaged dynamo. }\end{array}$ & $\begin{array}{c}\text { The coil, if the } \\
\text { dynamo is damaged, } \\
\text { just by replacing the } \\
\text { coil. }\end{array}$ & $\begin{array}{l}\text { All products have the } \\
\text { potential to become } \\
\text { waste, even if only the } \\
\text { damaged dynamo. }\end{array}$ & $\begin{array}{l}\text { Damaged } \\
\text { module only }\end{array}$ \\
\hline
\end{tabular}

*) Adding function: Emergency lights, electric mosquito repellent, USB slot, air freshener and backup electrical energy storage.

To provide an eco-fan based on consumer criteria, modularity concept is proposed to facilitate disassembly and improve product lifetime. To reduce energy consumption, the multifunction concept will also be an alternative. Finally, there are three alternatives to be studied, namely the modular concept, multifunctional, and a combination of modularmultifunctional. Based on the survey, respondents were very interested in the double function concept $(62.5 \%)$ with the desired additional features are room deodorizer $(37 \%)$, electric mosquito $(30 \%)$, emergency lamp $(17 \%)$, and others $(16 \%)$. The comparison between the current fan with the proposed in Table 2, Table 3 and Table 5.

Table 3. Comparison between the environmental impact value of existing and proposed fan

\begin{tabular}{|l|c|r|r|r|r|}
\hline Impact category & Unit & \multicolumn{1}{c|}{$\begin{array}{c}\text { Current } \\
\text { Fan }\end{array}$} & \multicolumn{1}{c|}{$\begin{array}{c}\text { Modular } \\
\text { Fan }\end{array}$} & \multicolumn{1}{c|}{$\begin{array}{c}\text { Multifunction } \\
\text { Fan }\end{array}$} & $\begin{array}{c}\text { Fan+Feature } \\
\text { Separated } \\
\text { Additional *) }\end{array}$ \\
\hline Climate change & kg CO2 eq & $23,235.50$ & $5,958.51$ & $34,437.45$ & $110,614.98$ \\
\hline Acidification & kg SO2 eq & 406.19 & 282.81 & 834.45 & $1,111.16$ \\
\hline Eutrophication & kg P eq & 1.05 & 0.25 & 1.47 & 7.88 \\
\hline Photochemical & kg NMVOC & 32.68 & 7.58 & 36.17 & 189.41 \\
\hline Fine DUST & kg PM2.5 eq & 10.43 & 1.53 & 12.18 & 46.34 \\
\hline Human toxic & CTUh & 0.00 & 0.00 & 0.00 & 0.01 \\
\hline Ecotoxicity & CTUe & $29,641.99$ & $6,244.77$ & $32,702.71$ & $197,742.07$ \\
\hline Metals Depletion & euro & $1,154.19$ & 272.01 & $1,181.39$ & $5,486.89$ \\
\hline Waste & MJ & $412,182.38$ & $402,081.56$ & $1,218,527.40$ & $412,585.39$ \\
\hline
\end{tabular}

Based on Table 3, the modular fan has much less environmental impact than the original fan, especially in ecotoxicity and climate change categories. So is the multifunction fan 
when compared with the fan along with other multifunction when designed separately. However, the multifunction fan has a very high environmental impact. The additional features on the fan will increase the use of materials and reduce the consumption of electrical energy.

Table 4. Comparison of the cost ( 1 batch $=1000$ unit $)($ Rupiah $)$

\begin{tabular}{|l|r|r|r|r|}
\hline \multicolumn{1}{|c|}{ Impact category } & \multicolumn{1}{|c|}{ Initial Fan } & Modular Fan & $\begin{array}{c}\text { Multifunction } \\
\text { Fan }\end{array}$ & $\begin{array}{c}\text { Fan+Feature } \\
\text { Separated Additional }\end{array}$ \\
\hline Total & $\mathbf{2 1 9 , 2 8 5 , 6 8 2}$ & $\mathbf{1 3 5 , 0 9 7 , 2 9 4}$ & $\mathbf{4 5 1 , 3 1 6 , 5 4 2}$ & $\mathbf{7 6 7 , 0 7 0 , 2 7 9}$ \\
\hline Climate change & $48,915,570$ & $12,543,788$ & $72,497,365$ & $232,865,548$ \\
\hline Acidification & $52,256,200$ & $36,384,063$ & $107,352,477$ & $142,950,774$ \\
\hline Eutrophication & 194,129 & 46,120 & 270,478 & $1,452,292$ \\
\hline Photochemical OF & $2,924,659$ & 678,076 & $3,237,034$ & $16,952,242$ \\
\hline Fine dust & $4,821,548$ & 708,709 & $5,633,280$ & $21,425,608$ \\
\hline Human toxicity & $15,543,154$ & $6,243,954$ & $18,576,658$ & $185,420,497$ \\
\hline Ecotoxicity & 658,457 & 138,719 & 726,447 & $4,392,574$ \\
\hline Metals Depletion & $17,998,483$ & $4,241,756$ & $18,422,524$ & $85,562,563$ \\
\hline Waste & $75,973,901$ & $74,112,107$ & $224,600,001$ & $76,048,185$ \\
\hline
\end{tabular}

The decrease in the initial environmental cost of the fan to the modular fan is approximately eighty million rupiah. However, the multi-function fan increases about two hundred thirty millions rupiah with the notes that multi-functional fan capacity reduces the eco cost by about three hundred million rupiahs compared to when the additional functionality is designed separately (Table 4). With the declining value of eco-cost, this will provide social impacts of prevention and maintenance of ecosystem quality, human health quality, and other natural resource aspects. Decreasing the environmental impact is one of sustainable production design criteria.

Products with the modular concept are easy to maintenance and repair, increase product life time, reduce waste and cost of environmental impact. The disadvantage is to increase the production process stage because it requires the interconnection component. The multifunctional product will increase the intensity of product usage and decrease the amount of product to be purchased. The disadvantage is to increase the price of the fan that affects consumer buying decisions, especially if consumers do not need the added features. The proposed alternative design is asked again to the respondent. The result is the majority chose stand fan with modularity concept without dual function (modularity $41 \%$, multifunction $24 \%$ and multifunction with modularity $35 \%$ ). From the environmental aspect, the first alternative has the least risk. The comparison between the existing fan and proposed fan is shown in Fig 2.

\section{Conclusion}

Integration GQFD with modular concept results in the product design that meets consumer needs and reduces the environmental impact. Although the concept of modularity must increase production process for the manufacturer, it enables the manufacturer to sell the product as the components. This will make it easier for consumers to do their own replacement of broken parts and add product innovation to the manufacturer. The study also reveals the fact that the level of consumer interest in fans will no longer be the price but is increasing to the need for quality and environmental protection (product life, energy saving, non-hazardous materials). And the concept of modularity can increase the life time and reduce the environmental impact. To improve the sustainability of the product, further study about Product Service-System (PSS) of the fan is needed. 


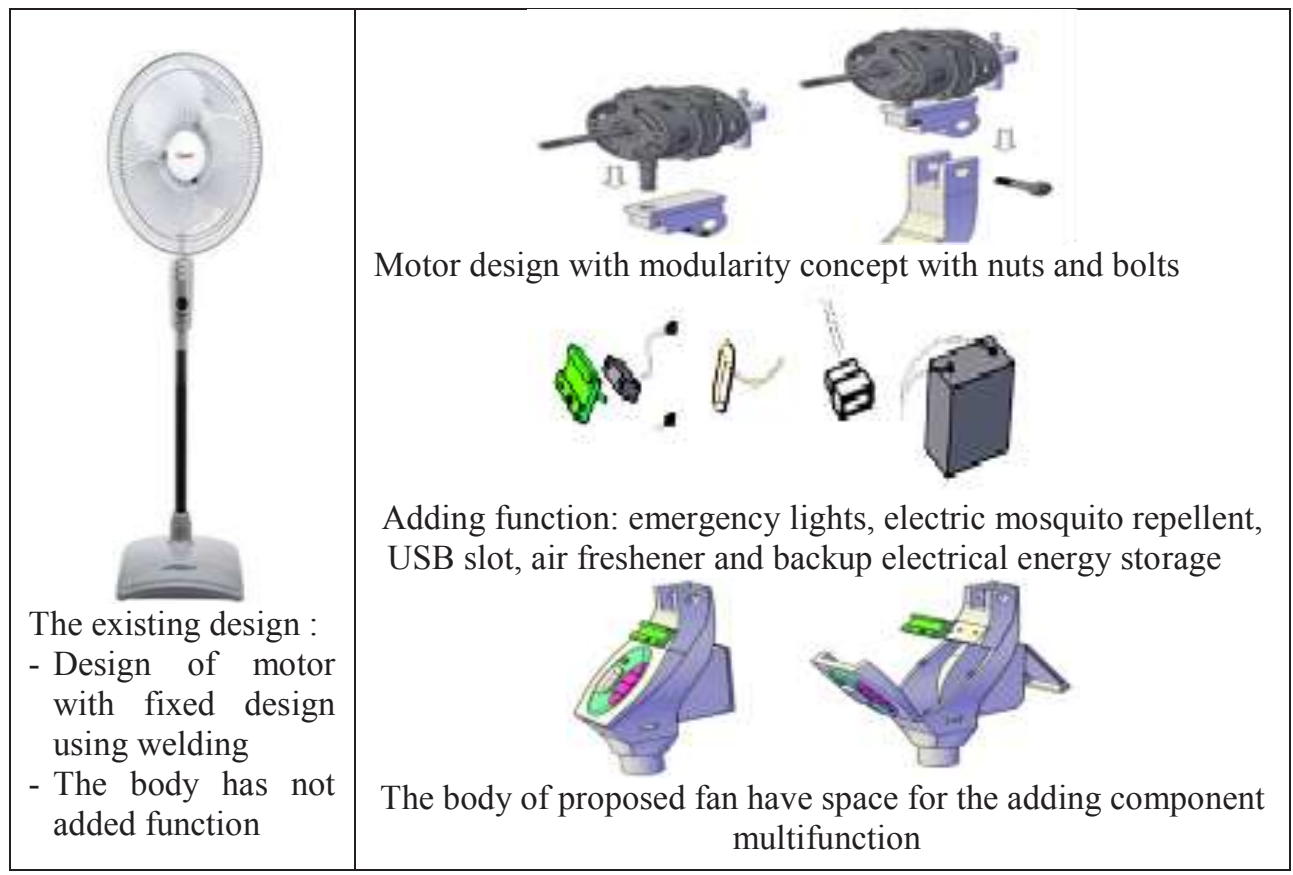

Fig 2. The comparison between the existing fan and proposed fan

\section{References}

1. G. Rebitzer, T. Ekvall, R. Frischknecht, D. Hunkeler, G. Norris, T. Rydberg, W.-P. Schmidt, S. Suh, B. P. Weidema, and D. W. Pennington, Environ. Int., 30 (2004).

2. K.T. Ulrich and D. Eppinger, Product Design and Development, $2^{\text {nd }}(1995)$

3. C. Mascle and H. P. Zhao, Int. J. Prod. Econ., 112, 5-17 (2008).

4. F. N. Puglieri, A. Ometto, and P. a C. Miguel, Prod. Manag. Dev., 9, 23-29 (2011).

5. S.D. Hochman and P.A. O'Connell, IEEE Int. Symp. On Elect. and Env (1993)

6. K. Masui, T. Sakao and A. Inaba, IEEE (2001)

7. S. Vinodh and G. Rathod, J. Clean. Prod., 18, 8, (2010).

8. C.S. Wang, P.Y. Lin, and T.R. Chang, Proc. 2010 14th Int. Conf. CSCWD 1 ( 2010 )

9. J. K. Gershenson and G. J. Prasad, Int. J. Agil. Manuf., 1, no. 1, 1997.

10. T. AlGeddawy and H. ElMaraghy, CIRP Ann. - Manuf. Technol., 62, 1 (2013).

11. D. Collado-ruiz and S. F. Capuz-rizo, J. Mech. Des., 132 (2013).

12. Cacherat, N. Lecocq, and G. Kremer, Congr. Int. surl'Analyse du Cycle Vie (2011).

13. F. Salvador and V. H. Villena, J. Supply Chain Manag., 49, 1 (2013).

14. K. Kuan, D. C. Y. Foo, R. R. Tan, S. Kumaresan, and R. A. Aziz, CTEP, 9, 3(2007).

15. S. G. Andrae and O. Andersen, Int. J. Life Cycle Assess., 15, 8 (2010).

16. Q. Song, Z. Wang, J. Li, and X. Zeng, Waste Manag., 32,10 (2012).

17. Olowu, Law Environ. Dev. J., 8, 1 (2012).

18. Cabigiosu, F. Zirpoli, and A. Camuffo, Res. Policy, 42, 3 (2013).

19. M. K. Daws, Z. A. Ahmed, and A. A. Moosa, Jordan J. Mech. Ind. Eng., 3, 1 (2009).

20. H. Hsu, A. Y. Chang, and H. M. Kuo, WSEAS Trans. Comput., 11, 1 (2012).

21. K.J. Kim, H. Moskowitz, A. Dhingra, and G. Evans, Eur. J. Oper. Res., 121, 3(2000).

22. R. R. Hischier Inge, LCA Case Stud., 8, 4 (2003).

23. Bereketli and M. Erol Genevois, J. Clean. Prod., 54, (2013).

24. A. Susanty, S. Hartini, D. Puspitasari, P. Arsiwi. Mediter. J. of Soc. Sci., 6, (2015) 